Available online at GSC Online Press Directory

GSC Biological and Pharmaceutical Sciences

e-ISSN: 2581-3250, CODEN (USA): GBPSC2

Journal homepage: https://www.gsconlinepress.com/journals/gscbps

(RESEARCH ARTICLE)

\title{
Effect of boiling on bioactive compounds and radical scavenging activity of anthocyanin-rich vegetables: Red amaranth and red skin potato
}

\author{
Kamrunnaher Monalisa ${ }^{1,2,{ }^{*}}$, Rashid Mamunur ${ }^{1}$, Sayem A.S.M ${ }^{1}$ and Islam Md Zohurul ${ }^{1}$ \\ ${ }^{1}$ Department of Food Engineering and Tea Technology, School of Applied Sciences and Technology, Shahjalal University \\ of Science and Technology, Sylhet-3114, Bangladesh. \\ ${ }^{2}$ Department of Advanced Food Science and Technology, Graduate School of Marine Science and Technology, Tokyo \\ University of Marine Science and Technology, Japan.
}

Publication history: Received on 07 May 2019; revised on 20 May 2019; accepted on 24 May 2019

Article DOI: https://doi.org/10.30574/gscbps.2019.7.2.0085

\begin{abstract}
This study was conducted to determine the optimum boiling time resulting in maximum retention of the bioactive compounds and radical scavenging activity. For this analysis, two most commonly consumed anthocyanin-rich vegetables, red amaranth (Amaranthus tricolor) and red skin potato (Solanum tuberosum) were exposed to boiling for $0,1,5,10$, and 20 minutes. Then the effects of boiling times on physicochemical, bioactive compounds, and antioxidant activity by DPPH radical scavenging ability were analyzed. In physicochemical analysis, ash content was decreased significantly, and the $\mathrm{pH}$ value increased significantly as the boiling time increased $(\mathrm{p}<0.05)$. The \% of WSI was increased significantly as the boiling time for red amaranth as well as red skin potato $(\mathrm{p}<0.05)$ increased. The total polyphenol content (TPC), total anthocyanin content (TAC), total carotenoid content (TCC), and radical scavenging activity (RSA) of red amaranth and red skin potatoes were gradually reduced with the increasing of boiling time. The first - order kinetic model showed the good fit for the loss of total phenolic, carotenoids, anthocyanin, and DPPH radical scavenging activity of red amaranth and red skin potatoes with $0.86-0.98$ coefficient of determination $\left(R^{2}\right)$. The findings could encourage both the household boiling and the food industry to recommend specific boiling time to maintain vegetables' antioxidant properties.
\end{abstract}

Keywords: Antioxidant; D-value; Rate of loss; Red amaranth; Red skin potato

\section{Introduction}

"Eating more vegetables" is an ancient and reasonable advice for a healthy diet. Vegetables play an important role in preventing the development of cardiovascular diseases, diseases associated with aging, obesity, cancers and improving memory of humans [1]. The cancer and other action to prevent disease are supposedly due to the fact that vegetables contain not only abundant nutritional components, but also a large amount of antioxidants. In addition, vegetables are very low in calories and are usually consumed in fresh condition, as well as after processing and cooking. Most vegetables cooked prior to consumption, including amaranth and red skin potato. Cooking adds pleasant sensory characteristics to the final product, as well as being more digestible and microbiologically safer to eat. However, depending on the process methods, vegetable species and shapes, the effect may be either positive or negative [2]. Culinary processes induce significant changes in foods such as water loss, changes in the total fat content and fatty acid profile, degradation of thermo - labile compounds, and formation of other compounds due to heat - induced chemical reactions [3]. Phenolic compounds can also be affected by thermal processes and, consequently the antioxidant capacity of consumed vegetables too [4]. In recent years, increasing consumers' awareness towards bioactive components and

\footnotetext{
${ }^{*}$ Corresponding author

E-mail address: kamrunnaher.monalisa-fet@sust.edu
}

Copyright (C) 2019 Author(s) retain the copyright of this article. This article is published under the terms of the Creative Commons Attribution Liscense 4.0 
their potential health benefits, has forced them to search for vegetables which contain more functional bioactive compounds.

Most phenolic compounds are well known to be water - soluble and usually lost during boiling. The possible reason for this is easier release of phenolic from soft matrix and/or inactivation of polyphenol oxidase, which may be responsible for loss of phenolic in raw plants [5]. It is necessary to consider the losses of these nutrients while developing new products and/or processes. Knowledge of kinetics including reaction order and rate constant, especially during thermal processing, is very vital to predict the losses / gain. There are still limited data on the effects of boiling on nutritional, antioxidant properties and kinetic model of boiled vegetables. A more integrated analysis is needed to obtain insight into the effects of boiling on bioactive phytochemicals and antioxidant capacity of commonly consumed vegetables. The aim of this study is therefore to investigate the effects of water boiling time on physicochemical, bioactive compounds and antioxidant activity of red amaranth and red skin potato.

\section{Material and methods}

\subsection{Sample}

Red amaranth (Amaranthus tricolor L.) and red skin potato (Solanum tuberosum) were obtained from the local market (Sylhet, Bangladesh). Within 24 hours the samples were prepared in the common manner (e.g., hard stems and blemishes removed) and then washed, wiped, cut into almost equal small pieces, and mixed well [6].

\subsection{Boiling method}

The boiling of vegetable was performed using the method described by Kao et al. [6]. Two hundred milliliters of water was brought to boil in a $500 \mathrm{~mL}$ beaker. The beaker was covered to prevent water loss due to evaporation. Ten grams each of red amaranth and red skin potato were boiled separately for $0,1,5,10$, and 20 minutes respectively. The samples boiled for 0 minute were taken as control. After boiling the samples were drained and cooled rapidly in cold water. Then the samples were vacuum packed in polyethylene bags and store at $-20^{\circ} \mathrm{C}$.

\subsection{Physicochemical characterization}

Moisture, ash, $\mathrm{pH}$, and water solubility index (WSI) were determined in all samples. To evaluate the moisture content, a gravimetric assay was conducted [7]. Samples $(\sim 5 \mathrm{~g})$ were dried in an oven at $105^{\circ} \mathrm{C}$, followed by regular weighing up to a constant weight. Results were expressed as percentage (\%). The mineral content was assessed by incineration at $550{ }^{\circ} \mathrm{C}$ and results were expressed as percentage (\%) [7]. A pH meter (Model No. PH500) was used to measure the $\mathrm{pH}$ of the samples. The WSI were determined according to the Yagci and Gogus [8]. A total of $10 \mathrm{~g}$ of sample was boiled into $200 \mathrm{~mL}$ of distilled water. This solution was transferred to experimental tubes, centrifuged for $5 \mathrm{~min}$ at $3000 \mathrm{rpm}$, and allowed for 30 minutes to settle completely. An aliquot of $25 \mathrm{~mL}$ of the supernatant was transferred to pre-weighed petri dishes and immediately oven-dried at $105^{\circ} \mathrm{C}$ for $5 \mathrm{~h}$. The water solubility index (WSI) was calculated as the weight difference by following the equation (1) below-

$$
\text { WSI \% = (Weight of dissolved solid in supernatant/weight of dry solids) } \times 100
$$

\subsection{Determination of bioactive compounds}

\subsubsection{Preparation of extracts}

Ten grams of samples were taken in a centrifuge tube with $40 \mathrm{~mL} 60 \%$ ethanol. The mixture was homogenized for 1 minute under nitrogen flow. Then centrifuged at $1000 \mathrm{rpm}$ for 5 minutes at room temperature and the supernatant was collected. The precipitate was re-extracted by adding $20 \mathrm{~mL} \mathrm{60 \%} \mathrm{ethanol,} \mathrm{homogenized} \mathrm{for} \mathrm{further} 1$ minute, and centrifuged at $1000 \mathrm{rpm}$ for 5 minutes. This ethanol extraction was repeated four times, and the resulting supernatants were combined and dried under vacuum, at a temperature below $30^{\circ} \mathrm{C}$. The residue was then re-dissolved by ultrasonic agitation to a final volume of $20 \mathrm{~mL}$ in $60 \%$ ethanol, and extracts were stored at $-18{ }^{\circ} \mathrm{C}$ until analysis [5].

\subsubsection{Determination of total phenolic content (TPC)}

The total phenolic content was measured following the method described by Lemos et al. [9] with some modifications. In short, a sample solution aliquot $(500 \mu \mathrm{L})$ was mixed with $500 \mu \mathrm{L}$ of distilled water and $1 \mathrm{~mL}$ of Folin - Ciocalteu reagent, maintaining the mixture for 5 minutes. After adding $5 \mathrm{~mL}$ of sodium carbonate (5\%), the volume with distilled water was adjusted to $10 \mathrm{~mL}$. At room temperature, the reaction mixture was incubated for $1 \mathrm{~h}$. The absorbance was measured at $765 \mathrm{~nm}$ with a spectrophotometer (UV-2550, Shimadzu, Japan). Quantification was based on the gallic acid 
standard curve $\left(y=0.0004 x+0.0013, R^{2}=0.998\right)$. The results were expressed as micrograms gallic acid equivalent per gram of fresh sample weight.

\subsubsection{Determination of total anthocyanin content (TAC)}

The total anthocyanin content was determined by $\mathrm{pH}$ differential method following the procedure reported by Lemos et al. [9] with some modifications. In short, $1000 \mathrm{~g}$ of boiled sample in $20 \mathrm{~mL}$ of $95 \%$ ethanol was re-suspended: $1 \mathrm{M}$ $\mathrm{HCl}(3: 1)$, shaken in the dark for 24 hours, filtered and evaporated. The volume of the solution was then adjusted to 25 $\mathrm{mL}$ with $0.01 \% \mathrm{HCl}$. The absorption of each sample was measured against a blank at both $\mathrm{pH}<1.0$ and $\mathrm{pH} 4.5 \mathrm{using}$ a spectrophotometer at $700 \mathrm{~nm}$ and $520 \mathrm{~nm}$. The total contents of anthocyanin were calculated using Eq. (2) and was expressed as mg cyanindin-3- glucoside/100 $\mathrm{g}$ fresh weight, where $\mathrm{V}$ was the diluent volume, A was the absorbance (calculated from Eq. (3), M was the molecular weight of a reference pigment (cyanidin-3-glucoside)-449.2 g/mol, and $\varepsilon_{1}$ is the molar absorptivity $(29,600)$. Results were expressed as milligrams of cyanidine-3-glucoside equivalent (CGE) $100^{-1} \mathrm{~g}$ fresh weight.

$$
\begin{aligned}
& \mathrm{A}=\left(\mathrm{A}_{520}-\mathrm{A}_{700}\right) \mathrm{pH}_{1}-\left(\mathrm{A}_{520}-\mathrm{A}_{700}\right) \mathrm{pH}_{4.5} \\
& \mathrm{C}(\mathrm{mg} / \mathrm{g})=\mathrm{V} \times \mathrm{n} \times \mathrm{M} / \varepsilon_{1} \times \mathrm{m}
\end{aligned}
$$

\subsubsection{Determination of total carotenoids content (TCC)}

Total carotenoids content was determined by spectrophotometric method according to Vinha et al. [10]. Before quantification, each vegetable (raw and boiled) was submitted for previous extraction. Five grams of homogenized sample were added to $50 \mathrm{~mL}$ ethanol (60\%), wrapped in aluminum foil and shaken at room temperature for $30 \mathrm{~min}$. After filtration, $3 \mathrm{~mL}$ of supernatant was collected, and absorbance was measured at $445 \mathrm{~nm}$. The total carotenoid content (mg/100 $\mathrm{g}$ of fresh sample) was determined according to the following equation (4):

$$
\text { Total carotenoids }(\mathrm{mg} / 100 \mathrm{~g})=\left(\mathrm{A} \times \mathrm{y} \times 10^{6}\right) /(\mathrm{A} 1 \% \mathrm{~cm} \times 1000 \times \mathrm{w})
$$

Where, A represents the absorbance of the extract at $445 \mathrm{~nm}$; y is the volume of extract (mL); $A 1 \% \mathrm{~cm}$ represents the extinction coefficient of carotenoids (A1 \% cm = 2592), and $\mathrm{w}$ is the sample weight $(\mathrm{g})$.

\subsubsection{Determination of antioxidant activity by DPPH•radical-scavenging activity}

A Diphenyl-1-picrylhydrazyl (DPPH) radical scavenging assay was performed according to the method adopted by Olugbami et al. [11]. In a 96-well flat - bottomed micro - plate on ice, a $20 \mu \mathrm{L}$ aliquot of the extract was added to $20 \mu \mathrm{L}$ of distilled water. After $200 \mu \mathrm{L}$ of $118.3 \mathrm{mg} / \mathrm{L} \mathrm{DPPH}$ radical solution was added, the mixture was mixed thoroughly. Ethanol was used to produce the DPPH radical solution. After the plates were stored in the dark for 30 min on ice, the absorbance was measured using a plate reader (1510, Thermo Fisher, USA) at $515 \mathrm{~nm}$. A control containing $20 \mu \mathrm{L}$ of ethanol (no extract) was also included in each plate. The DPPH radical scavenging activity was calculated using Eq. (5).

$$
\text { DPPH radical scavenging activity }(\%)=\left(\frac{\mathrm{Abs}_{\mathrm{control}}-\mathrm{Abs}_{\text {sample }}}{\mathrm{Abs}_{\mathrm{control}}}\right) \times 100
$$

\subsection{Kinetic analysis}

The data obtained from the degradation of total phenolic content, total carotenoid content, total anthocyanin content, and DPPH radical scavenging activity of red amaranth and red skin potato was subjected to first order kinetic analysis [12] using the following first orders kinetic Eq. (6)

$$
\mathrm{C}=\mathrm{C}_{\mathrm{o}} \exp (-\mathrm{kt})
$$

Where, $\mathrm{k}$ is the first order rate constant, $\mathrm{t}$ is boiling time, $\mathrm{C}_{\mathrm{o}}$ is initial concentration, $\mathrm{C}_{\mathrm{t}}$ is their concentrations after heating for time $(\mathrm{t})$.

The thermal resistance time or decimal reduction time (D values), the time required to reduce the nutrient concentration by $90 \%$, was related to reaction rate constants following equation (7)-

$$
\mathrm{D}=\frac{2.303}{\mathrm{k}}
$$




\subsection{Statistical Analysis}

The results were shown as the mean \pm standard deviation of three parallel measurements. Differences between variables were tested for significance using analysis of variance. All data were the mean values of three replicates and the data were analyzed for significance at the $\mathrm{p}<0.05$ level. Non - linear regression analysis equipped kinetic models with Origin pro 8.5 statistical software.

\section{Results and discussion}

\subsection{Effect of boiling on physicochemical properties of red amaranth and red skin potato}

Physicochemical properties of red amaranth and red skin potato during different boiling time are presented in Table 1 and 2 respectively. The result shows that the moisture content in red amaranth and red potato was not changed significantly with increasing the boiling times. Whereas the ash content in both samples was significantly reduced by increasing the boiling time. These results are consistent with the findings reported for the boiling and leaching of potatoes by Bethke and Jansky [13], who also found reductions in phosphorus, magnesium, sulfur, zinc, manganese and iron during boiling in 6 potato cultivars tubers. The $\mathrm{pH}$ value increased by increasing the boiling time for both red amaranth and red potato $(\mathrm{p}<0.05)$.

Table 1 Physicochemical properties of red amaranth

\begin{tabular}{|c|c|c|c|c|c|}
\hline $\begin{array}{l}\text { Boiling Time } \\
\text { (min) }\end{array}$ & $\begin{array}{l}\text { Moisture } \\
\text { (\%) }\end{array}$ & Content & Ash Content (\%) & pH & $\begin{array}{l}\text { Water } \\
\text { Solubility } \\
\text { Index (\% WSI) }\end{array}$ \\
\hline 0 & $86.62 \pm 1.90^{a}$ & & $1.3 \pm 0.01^{\mathrm{a}}$ & $6.08 \pm 0.04^{d}$ & - \\
\hline 1 & $92.23 \pm 2.20^{\mathrm{a}}$ & & $0.95 \pm 0.01^{b}$ & $6.85 \pm 0.01^{\mathrm{c}}$ & $1.69 \pm 0.27^{d}$ \\
\hline 5 & $91.32 \pm 2.40^{\mathrm{a}}$ & & $0.92 \pm 0.01^{c}$ & $7.45 \pm 0.05^{b}$ & $3.45 \pm 0.92^{c}$ \\
\hline 10 & $90.46^{ \pm 2.57^{\mathrm{a}}}$ & & $0.90 \pm 0.01^{\mathrm{d}}$ & $7.45 \pm 0.07^{b}$ & $6.61 \pm 1.45^{b}$ \\
\hline 20 & $90.27 \pm 2.64^{a}$ & & $0.85 \pm 0.01^{\mathrm{e}}$ & $7.50 \pm 0.04^{\mathrm{a}}$ & $16.69 \pm 3.13^{a}$ \\
\hline
\end{tabular}

All values are of means of triplicate determination expressed on wet weight basis \pm standard deviation. Mean values in the following row sharing a common letter are not statistically significant $(\mathrm{p}<0.05)$.

This may occur due to the release of ascorbic acid from cell disintegration and along with its destruction during boiling. The $\%$ of water solubility index increased with increasing boiling time in both red amaranth and red skin potatoes. This finding may be due to the water leaching of soluble sugars and organic acids.

Table 2 Physicochemical properties of red skin potato

\begin{tabular}{lllll}
\hline $\begin{array}{l}\text { Boiling Time } \\
\text { (min) }\end{array}$ & $\begin{array}{l}\text { Moisture Content } \\
\mathbf{( \% )}\end{array}$ & $\begin{array}{l}\text { Ash Content } \\
\mathbf{( \% )}\end{array}$ & pH & $\begin{array}{l}\text { Water Solubility } \\
\text { Index (\% WSI) }\end{array}$ \\
\hline 0 & $81.54 \pm 2.35^{\mathrm{A}}$ & $1.19 \pm 0.05^{\mathrm{A}}$ & $6.00 \pm 1.00^{\mathrm{D}}$ & -- \\
1 & $85.23 \pm 2.20^{\mathrm{A}}$ & $0.98 \pm 0.05^{\mathrm{B}}$ & $6.58 \pm 1.11^{\mathrm{A}}$ & $0.70 \pm 0.02^{\mathrm{D}}$ \\
5 & $85.30 \pm 2.30^{\mathrm{A}}$ & $0.89 \pm 0.03^{\mathrm{C}}$ & $6.51 \pm 1.92^{\mathrm{B}}$ & $1.35 \pm 0.10^{\mathrm{C}}$ \\
10 & $84.33 \pm 2.35^{\mathrm{A}}$ & $0.85 \pm 0.01^{\mathrm{D}}$ & $6.48 \pm 2.01^{\mathrm{CB}}$ & $2.27 \pm 0.50^{\mathrm{B}}$ \\
20 & $84.50 \pm 2.40^{\mathrm{A}}$ & $0.80 \pm 0.04^{\mathrm{E}}$ & $6.50 \pm 1.51^{\mathrm{B}}$ & $4.67 \pm 1.05^{\mathrm{A}}$
\end{tabular}




\subsection{Effect of boiling on bioactive compounds of red amaranth and red skin potato}

Bioactive compounds are extra - nutritional constituents, available mainly in fruits and vegetables that provide additional health benefits to humans. During cooking by boiling at the domestic level, due to thermal degradation, dilution and leaching into the water used for treatment, the composition and content of various bioactive components are very likely to be affected [14-15]. Losses of these nutrients must be taken into account while developing new products and/or processes. Kinetic models are used for fast quality assessment and prediction; in addition, they can be employed to predict the influence of processing on critical quality parameters. In this study, we investigated the effect of boiling in the \% of loss and first order of degradation kinetics of total polyphenol content (TPC), total anthocyanin content (TAC), total carotenoid content (TCC), and DPPH radical scavenging activity (RSA) of red amaranth and red skin potato.

\subsubsection{The effect of boiling on total phenolic content (TPC)}

The effect of boiling time on total phenolic content of raw, and boiled red amaranth and red skin potato is shown in Figure 1 and the $\%$ of losses is shown in Table 3. In the present study, the TPC in red amaranth was found to decrease significantly by increasing the boiling time and the loss at 20 minutes of boiling was about $38.21 \pm 2.01 \%$ of its initial level. Domestic boiling opens the cell matrix, facilitates the extractability and bio-accessibility of total phytochemicals, promotes the release of bound phytochemicals and forms soluble low - molecular weight phytochemicals that can be easily degraded by the heating process and leads to a decrease in total phenolic content [16].

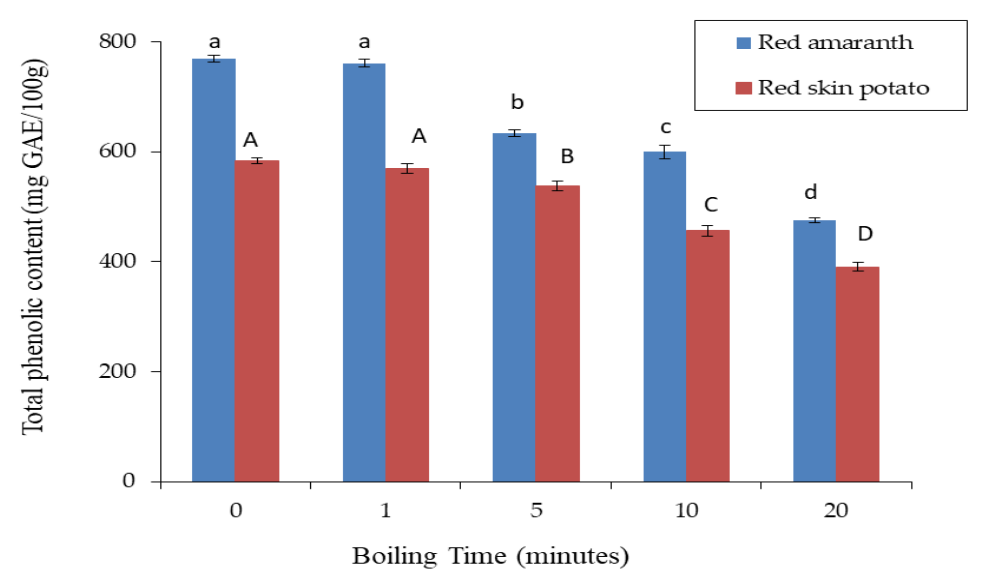

Figure 1 Total phenolic content of red amaranth and red skin potato at the different boiling time

The first order kinetic model for the degradation of bioactive compounds during boiling treatment was determined in agreement with other studies [17]. A graph was plotted between boiling time and $C_{t} / C_{o}$ values in order to evaluate the relationship between boiling time and degradation of TPC compounds [Figure 5 (a)]. From the 1st order kinetics model it can be seen that the loss rate was about $0.025 \mathrm{mg} / \mathrm{min}$ and the thermal resistance time (D) value was $92.12 \mathrm{~min}$.

The $\mathrm{R}^{2}$ values obtained from the graph were 0.961 indicated a good correlation between the predicted value and the experimental values and also indicated a strong correlation between the boiling time and the TPC content in red amaranth.

Similarly, the raw red skin potato contained TPC $583.65 \pm 2.40 \mathrm{mg}$ GAE/100 g and gradually decreased to $390.65 \pm 4.05$ $\mathrm{mg} \mathrm{GAE} / 100 \mathrm{~g}$ at 20 minutes of boiling, resulting in losses of $33.06 \pm 1.94 \%$ (Table 3 ). The findings are lower with the results reported by Perla, Holm, \& Jayanty [18], who found that boiling reduced the total phenolic content by about $62.02 \%$. In the kinetic study, it was found that the D - value is $115.15 \mathrm{~min}$ in red skin potato and the loss rate is 0.020 $\mathrm{mg} / \mathrm{min}$ (Table 3 ). The $\mathrm{R}^{2}$ value is 0.98 indicate a strong relation of TPC with time (Table 3 ). Increases in cooking time and temperature can exacerbate the loss of phenolic compounds due to thermal degradation or the transfer of hydrophilic phenolics from red amaranth and red skin potatoes to water [16]. Lemos et al. [9] also reported that cooking had a detrimental effect on the total phenolic levels in purple majesty potatoes. 
Table 3 The percentage (\%) of loss, kinetic parameter estimated (k) and statistical values of first-order kinetic model of bioactive compounds and antioxidant activity

\begin{tabular}{|c|c|c|c|c|c|c|}
\hline \multirow{2}{*}{ Parameter } & \multirow{2}{*}{ Name } & \multirow{2}{*}{$\begin{array}{l}\text { Time } \\
\text { (min) }\end{array}$} & \multirow{2}{*}{ The $\%$ of loss } & \multicolumn{3}{|c|}{ Degradation kinetics } \\
\hline & & & & D & $\mathbf{k}$ & $\mathbf{R}^{2}$ \\
\hline \multirow{10}{*}{ Total phenolic content } & \multirow{5}{*}{ Red amaranth } & 0 & - & \multirow{5}{*}{92.12} & \multirow{5}{*}{0.025} & \multirow{5}{*}{0.961} \\
\hline & & 1 & $1.10 \pm 0.02$ & & & \\
\hline & & 5 & $17.74 \pm 1.27$ & & & \\
\hline & & 10 & $22.08 \pm 2.10$ & & & \\
\hline & & 20 & $38.21 \pm 2.01$ & & & \\
\hline & \multirow{5}{*}{ Red skin potato } & 0 & - & \multirow{5}{*}{115.15} & \multirow{5}{*}{0.020} & \multirow{5}{*}{0.981} \\
\hline & & 1 & $2.40 \pm 0.90$ & & & \\
\hline & & 5 & $7.82 \pm 1.03$ & & & \\
\hline & & 10 & $21.81 \pm 1.21$ & & & \\
\hline & & 20 & $33.06 \pm 1.94$ & & & \\
\hline \multirow{10}{*}{ Total anthocyanin content } & \multirow{5}{*}{ Red amaranth } & 0 & - & \multirow{5}{*}{100.13} & \multirow{5}{*}{0.023} & \multirow{5}{*}{0.972} \\
\hline & & 1 & $3.78 \pm 0.57^{c}$ & & & \\
\hline & & 5 & $13.35 \pm 1.67 c$ & & & \\
\hline & & 10 & $23.62 \pm 2.0^{\mathrm{b}}$ & & & \\
\hline & & 20 & $34.92 \pm 1.9^{a}$ & & & \\
\hline & \multirow{5}{*}{ Red skin potato } & 0 & - & \multirow{5}{*}{76.76} & \multirow{5}{*}{0.030} & \multirow{5}{*}{0.086} \\
\hline & & 1 & $4.05 \pm 0.72^{\mathrm{d}}$ & & & \\
\hline & & 5 & $21.90 \pm 1.23^{c}$ & & & \\
\hline & & 10 & $32.12 \pm 2.78^{b}$ & & & \\
\hline & & 20 & $37.82 \pm 2.31^{\mathrm{a}}$ & & & \\
\hline \multirow{10}{*}{ Total carotenoids content } & \multirow{5}{*}{ Red amaranth } & 0 & - & & & \\
\hline & & 1 & $3.03 \pm 0.02^{c}$ & & & \\
\hline & & 5 & $5.88 \pm 0.03^{c}$ & 329.00 & 0.008 & 0.953 \\
\hline & & 10 & $9.09 \pm 0.19 \mathrm{~b}$ & & & \\
\hline & & 20 & $15.65 \pm 0.28^{\mathrm{a}}$ & & & \\
\hline & & 0 & - & & & \\
\hline & & 1 & $1.33 \pm 0.01^{c}$ & & & \\
\hline & Red skin potato & 5 & $2.81 \pm 0.01^{c}$ & 329.00 & 0.007 & 0.989 \\
\hline & & 10 & $7.98 \pm 0.51^{b}$ & & & \\
\hline & & 20 & $14.64 \pm 0.19^{\mathrm{a}}$ & & & \\
\hline & & 0 & - & & & \\
\hline & Red amaranth & 1 & $1.80 \pm 0.57^{\mathrm{d}}$ & & & \\
\hline & & 5 & $14.49 \pm 1.67^{c}$ & 85.29 & 0.027 & 0.968 \\
\hline & & 10 & $28.01 \pm 2.0^{\mathrm{b}}$ & & & \\
\hline DPPH radical scavenging & & 20 & $38.36 \pm 1.90^{a}$ & & & \\
\hline activity & & 0 & - & & & \\
\hline & & 1 & $3.56 \pm 0.72^{d}$ & & & \\
\hline & Red skin potato & 5 & $7.68 \pm 1.23^{c}$ & 143.93 & 0.016 & 0.903 \\
\hline & & 10 & $18.06 \pm 2.78^{b}$ & & & \\
\hline & & 20 & $26.39 \pm 2.31^{\mathrm{a}}$ & & & \\
\hline
\end{tabular}




\subsubsection{Effect of boiling time on total anthocyanin content (TAC)}

Anthocyanins are water - soluble colored pigments belonging to the phenolic group. The pigments are in glycosylated forms. Anthocyanins responsible for colors, red, purple, and blue, are present in fruits and vegetables. Anthocyanins are considered one of the most important pigment and health - promoting compounds in red amaranth and red skin potatoes. The compounds, however, are easily dissolved in water and broken down by thermal treatment [19]. Several boiling times were observed to induce distinct losses of total anthocyanin (Figure 2). The present study revealed that when prolonging their boiling time, the anthocyanin content was greatly reduced in both red amaranth and red skin potato. The anthocyanin content in raw red amaranth was $89.25 \pm 1.96 \mathrm{mg}$ CGE/100 g which was gradually reduced to $57.89 \pm 2.17 \mathrm{mg}$ CGE/100 g after 20 minutes of boiling, which is about $34.92 \pm 1.9 \%$ loss (Table 3 ).

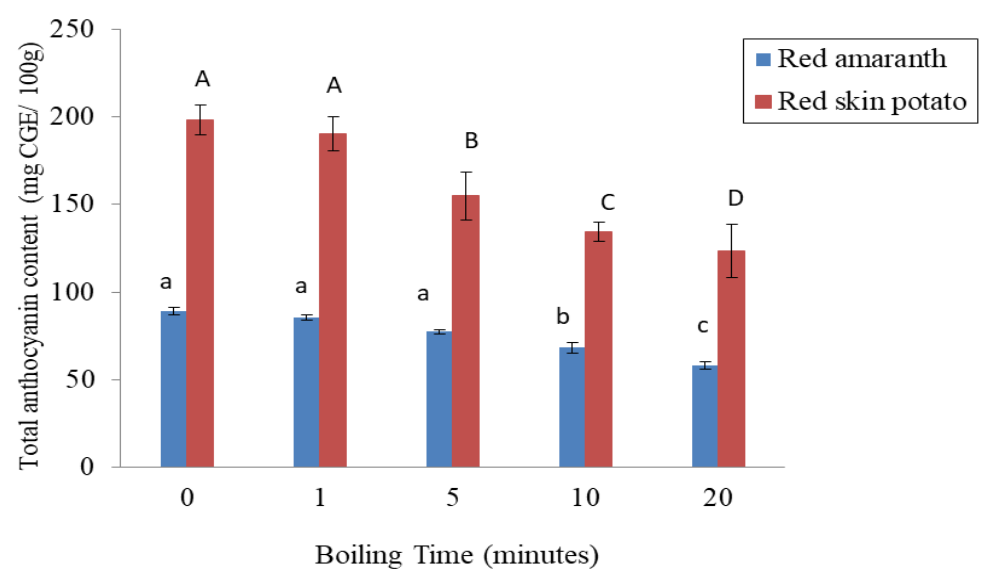

Figure 2 Total anthocyanin content of red amaranth and red skin potato at the different boiling time

In case of kinetic study, the rate of loss was observed $0.023 \mathrm{mg} / \mathrm{min}$ and D-value was 100.13 . Similarly, the anthocyanin content in red skin potato gradually decreased from $198.30 \pm 8.63$ (raw/0 min boiled) to 123.30 $\pm 15.16 \mathrm{mg}$ CGE/100 g at 20 minutes of boiling. At 20 minutes of boiling, the $\%$ of loss in red skin potato was $37.82 \pm 2.31 \%$. The loss rate in the red skin potato was estimated at $0.030 \mathrm{mg}$ CGE / minute and D - value was 76.76. The higher R2 values indicated that the losses of TAC during the boiling period followed the first order kinetics. The experimental and predicted data are presented in the Figure 5. Tian et al. [20] reported that the anthocyanin of purple skinned potato was reduced during boiling and which was about the losses of $14.66 \%$. However, the extent of anthocyanin loss reported by these authors was different, which may have been due to the different cooking times, temperatures and pretreatments used in the different studies. The findings of the present study is in accordance with Ioannou et al. [21] who were reported that anthocyanin could be lost due to combined effect of thermal degradation and the soaking in the boiled water.

\subsubsection{Effect of boiling time on total carotenoid content (TCC)}

Carotenoids are isoprenoid molecules that are widespread in nature and have a wide range of functions due to their biological antioxidants (i.e. protecting against age - related macular degeneration and cataracts and reducing diseases, including cardiovascular diseases and cancer). It is a class of lipophilic compounds, less susceptible to leaching and less sensitive to heat. The changes in TCC during boiling at different boiling times are shown in Figure 3. In this study, the total carotenoid content in red amaranth $(\mathrm{p}<0.05)$ was not significantly changed until 10 minutes of boiling, but at 20 minutes TCC was reduced to $1.67 \mathrm{mg} / 100 \mathrm{~g}$, which was about $15.56 \%$ loss (Table 3). The TCC was also found to be significantly reduced in red skin potato after 10 minutes of boiling. At 20 minutes of boiling, the percentage of loss in both vegetables was $14-15 \%$. 


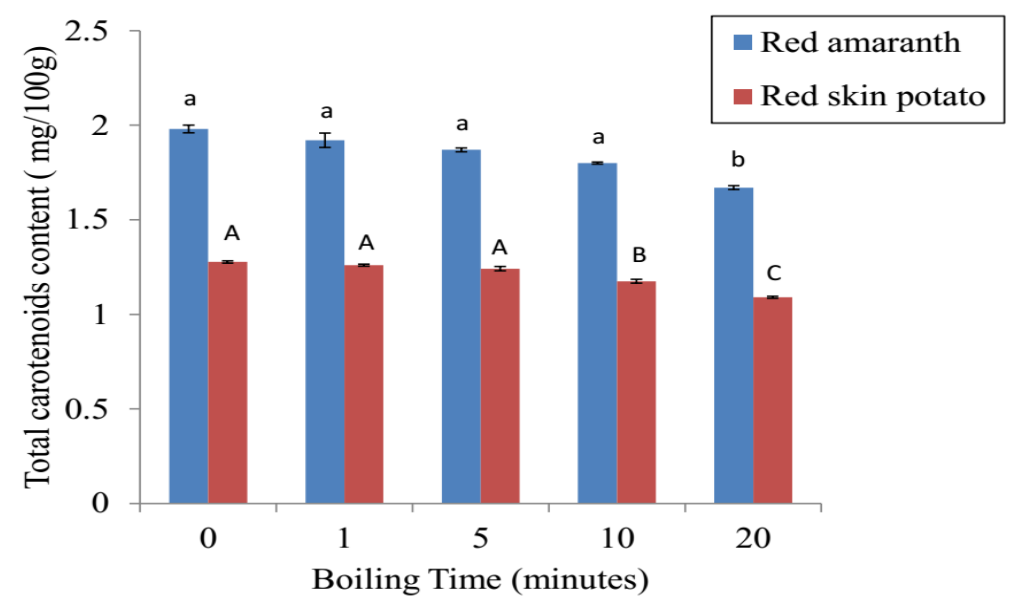

Figure 3 Total carotenoids contents of red amaranth and red potato at the different boiling duration

This can be attributed to disruption of cell walls with food processing procedures, facilitating their release from proteins. But this behavior can vary with the food matrix, as these bioactive compounds are reported to increase and decrease. Unlike phenolics and anthocyanins, there are few data available on the effects of boiling time on carotenoids in red amaranth and red skin potato. In a study with five tropical leafy vegetables from Africa, Djuikwo et al. [22] also recorded losses of total carotenoids from 5 to $20 \%$ after 10 minutes boiling. Kao et al. evaluated the effect of boiling in various carotenoid-rich green leafy vegetables; including Thai basil leaves and cilantro, and noted that total carotenoids content reached the maximum after boiling those vegetables for 5 minutes and 10 minutes [6]. A negative effect on the total carotenoids contents of the vegetables was noticed with more boiling time. The first order kinetic study showed that the rate of TCC loss was almost same 0.008 and $0.007 \mathrm{mg} / \mathrm{min}$ in red amaranth and red skin potato respectively. The time of thermal resistance was found $329.00 \mathrm{~min}$ in both vegetables. The predicted value and experimental values of the TCC and strong correlations (higher $\mathrm{R}^{2}$ values 0.95 and 0.98 ) as shown in the Figure 5 (c) demonstrated that the losses of total carotenoid vs boiling time followed the first order kinetics.

\subsection{Effect of boiling on DPPH Radical Scavenging Activity (RSA)}

In this study the total antioxidant activity was measured by DPPH Radical Scavenging Activity (RSA). The RSA levels in raw red amaranth and red skin potato and its changes after boiling is summarizes in Figure 4. RSA was found to have gradually reduced in both boiled red amaranth and red skin potato. In the boiled tissues of red amaranth after boiling for 5 min RSA decreased to $41.72 \pm 0.89 \%$ which was $14.49 \pm 1.52 \%$ loss from its initial level. Further significant loss of RSA to $38.36 \pm 2.94 \%$ was observed when the boiling time was extended to 20 minutes (Table 3). Similar trend was found in red skin potato, which significantly increased by increasing the boiling time.

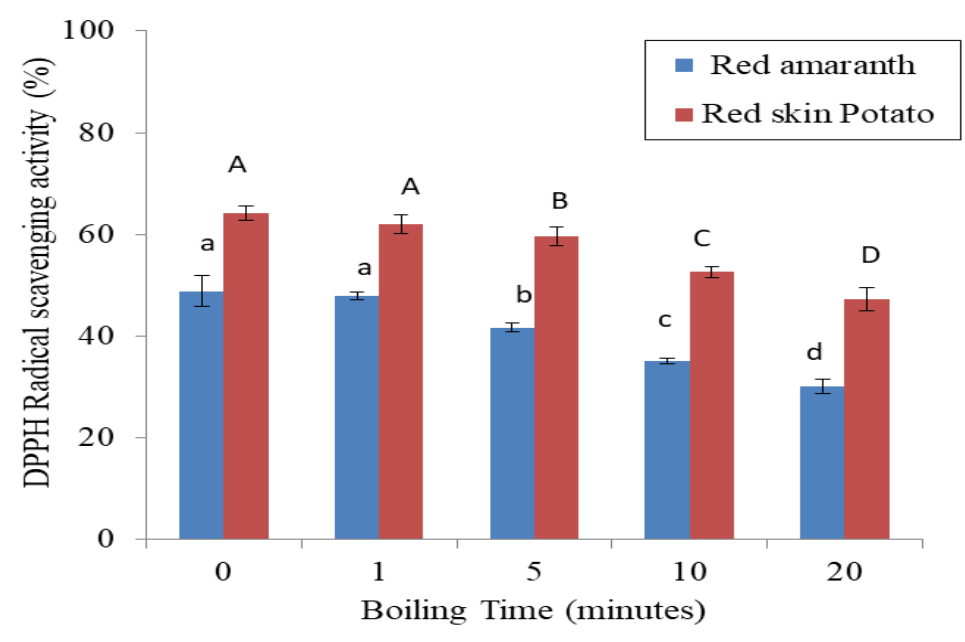

Figure 4 DPPH Radical Scavenging Activity (RSA) in red amaranth and red skin potato

The rate of degradation of TAA was estimated by first order kinetic model (Figure $5 \mathrm{~d}$ ). The result showed that the loss rate of red amaranth and red skin potato was $0.027 / \mathrm{min}$ and $016 / \mathrm{min}$ respectively. The thermal resistance of red 
amaranth and red skin potato was 85.29 and 143.93 min respectively (Table 3). Puupponen-Pimia et al. reported that the cauliflower DPPH index decreased by $23 \%$ during blanching in water [23]. The loss of antioxidant activity in cooked tissue during blanching was due to the large surface area of the vegetables in contact with the water [24]. Antioxidant levels were reported to decrease after aqua thermal treatment of broccoli [25] and selected cruciferous vegetables [26].
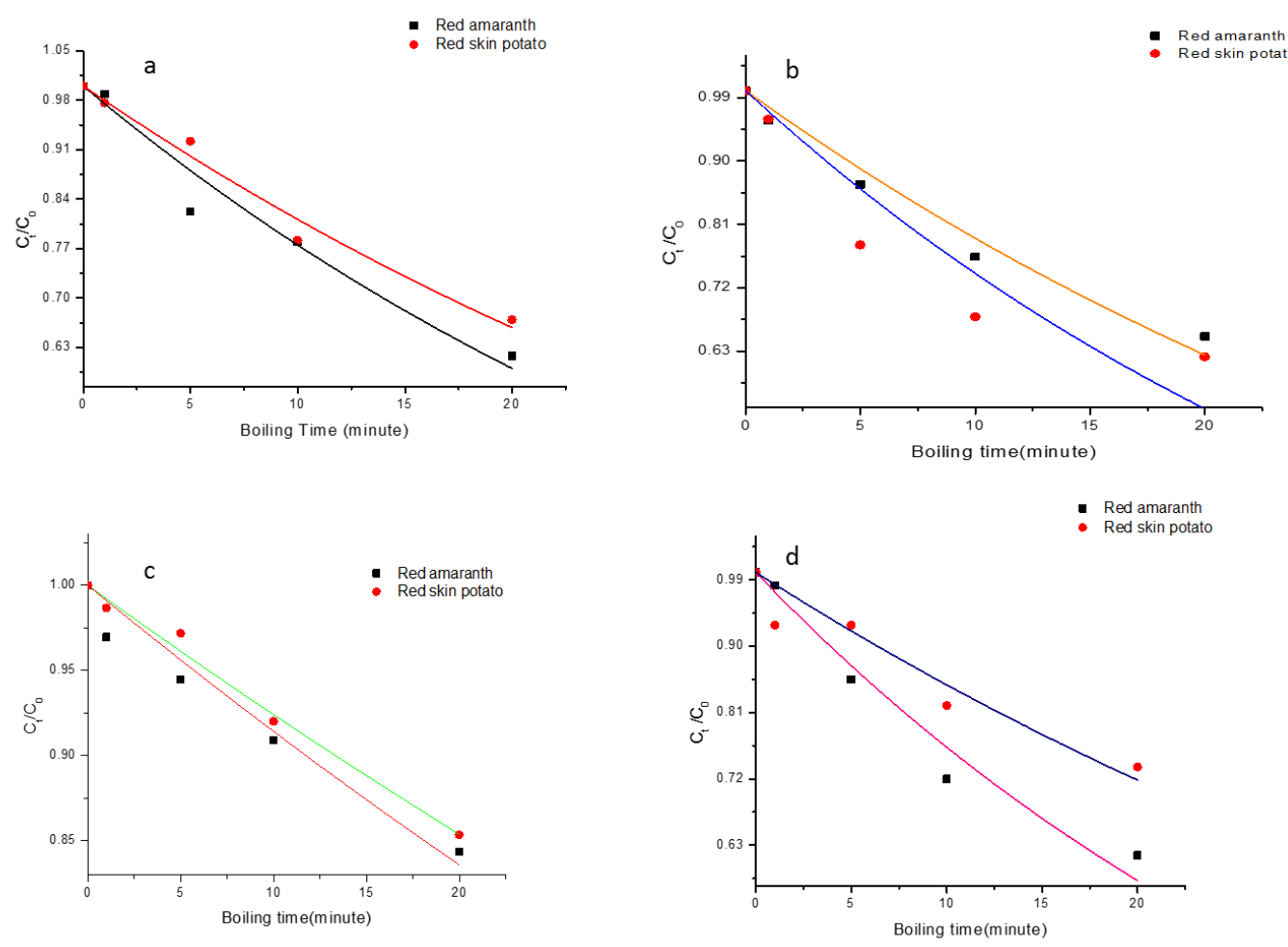

Figure 5 First order kinetics of (a) Total phenolic content, (b) Total anthocyanin content, (c) Total carotenoid content, and (d) DPPH radical scavenging activity (RSA)

\section{Conclusion}

The effects of boiling on physicochemical, antioxidants and degradation rate during different boiling time of red amaranth and red skin potatoes were evaluated. The present study indicated that total polyphenol, anthocyanin, and antioxidant activity of red amaranth and red skin potatoes were significantly reduced when prolonging the boiling time, whereas total carotenoid contents was less affected by boiling. The first order kinetic model was determined as the most appropriate model to represents the degradation of polyphenols, anthocyanin, carotenoids and total antioxidant activity of red amaranth and red skin potatoes during boiling. The results of our investigation demonstrated that it is vital to use less boiling time to minimize the loss of polyphenols, anthocyanin and total antioxidant activity. We concluded that the assessment of the effects of boiling time on the bioactive compounds and antioxidant activity of red amaranth and red skin potatoes helps in dietary survey evaluating, planning intake and also used for making recommendations on the food processing techniques to be chosen for preserving the most functional and bioactive compounds of vegetables.

\section{Compliance with ethical standards}

\section{Acknowledgments}

The authors gratefully acknowledge the financial support (project code: AS/2018/1/16), for this research to the University Research Centre, Shahjalal University of Science and Technology, Bangladesh.

\section{Disclosure of conflict of interest}

Author's has no conflict of interest. 


\section{References}

[1] Bidlack, WR. (2000). Phytochemicals as Bioactive Agents, Technomic Pub.

[2] Bernhardt S and Schlich E. (2006). Impact of different cooking methods on food quality: Retention of lipophilic vitamins in fresh and frozen vegetables. Journal of Food Engineering, 77(2), 327-333.

[3] Miglio C, Chiavaro E, Visconti A, Fogliano V and Pellegrini N. (2008). Effects of different cooking methods on nutritional and physicochemical characteristics of selected vegetables. Journal of Agricultural and Food Chemistry, 56(1), 139-147.

[4] Ramirez Anaya J, Del P, Samaniego Sanchez C, Castaneda Saucedo MC, Villalon Mir M and De la Serrana HLG. (2015). Phenols and the antioxidant capacity of Mediterranean vegetables prepared with extra virgin olive oil using different domestic cooking techniques. Food Chemistry, 188 (430-438).

[5] Ferracane R, Pellegrini N, Visconti A, Graziani G, Chiavaro E, Miglio C and Fogliano V. (2008). Effects of different cooking methods on antioxidant profile, antioxidant capacity, and physical characteristics of Artichoke. Journal of Agricultural and Food Chemistry, 56, 8601-8608.

[6] Kao FJ, Chiu YS and Chiang WD. (2014). Effect of water cooking on antioxidant capacity of carotenoid-rich vegetables in Taiwan. Journal of Food and Drug Analysis, 22(2), 202-209.

[7] AOAC. (2005). Official Methods of Analysis of AOAC International - 18th Edition, Revision 3, Maryland, USA: The Association.

[8] Yagci S and Gogus F. (2009). Development of extruded snack from food by-products: A response surface analysis. Journal of Food Process Engineering, 32(4), 565-586.

[9] Lemos MA, Aliyu MM and Hungerford G. (2015). Influence of cooking on the levels of bioactive compounds in Purple Majesty potato observed via chemical and spectroscopic means. Food Chemistry, 173, 462-467.

[10] Vinha AF, Alves RC, Barreira SVP, Costa ASG and Oliveira MBPP. (2015). Impact of boiling on phytochemicals and antioxidant activity of green vegetables consumed in the Mediterranean diet. Food \& Function, 6(4), 1157-1163.

[11] Olugbami JO, Gbadegesin MA and Odunola OA. (2015). In vitro free radical scavenging and antioxidant properties of ethanol extract of Terminalia glaucescens. Pharmacognosy Research, 7(1), 49-56.

[12] Sapei L and Hwa L. (2014). Study on the kinetics of vitamin C degradation in fresh strawberry juices. Procedia Chemistry, 9, 62-68.

[13] Bethke PC and Jansky SH (2008). The effects of boiling and leaching on the content of potassium and other minerals in potatoes. Journal of Food Science, 73(5), H80-H85.

[14] Hwang IG, Shin YJ, Lee S, Lee J and Yoo SM (2012). Effects of different cooking methods on the antioxidant properties of red pepper (Capsicum annuum L.). Preventive Nutrition and Food Science, 17(4), 286-92.

[15] Ismail A, Marjan ZM and Foong CW. (2004). Total antioxidant activity and phenolic content in selected vegetables. Food Chemistry, 87(4), 581-586.

[16] Palermo M, Pellegrini N and Fogliano V. (2014).The effect of cooking on the phytochemical content of vegetables. Journal of the Science of Food and Agriculture, 94(6), 1057-1070.

[17] Nakilcioglu Tas E and Otles S. (2017). Degradation kinetics of bioactive compounds and antioxidant capacity of Brussels sprouts during microwave processing. International Journal of Food Properties, 20, S2798-S2809.

[18] Perla V, Holm DG and Jayanty SS (2012). Effects of cooking methods on polyphenols, pigments and antioxidant activity in potato tubers. LWT - Food Science and Technology, 45(2), 161-171.

[19] Patras A, Brunton NP, O'Donnell C and Tiwari BK. (2010). Effect of thermal processing on anthocyanin stability in foods; mechanisms and kinetics of degradation. Trends in Food Science \& Technology, 21(1), 3-11.

[20] Tian J, Chen J, Lv F, Chen S, Chen J, Liu D and Ye X. (2016). Domestic cooking methods affect the phytochemical composition and antioxidant activity of purple fleshed potatoes. Food Chemistry, 197, 1264-1270.

[21] Ioannou I, Hafsa I, Hamdi S, Charbonnel C and Ghoul M. (2012). Review of the effects of food processing and formulation on flavonol and anthocyanin behaviour. Journal of Food Engineering, 111(2), 208-217.

[22] Djuikwo VND, Ejoh RA, Gouado I, Mbofung CM and Tanumihardjo SA. (2011). Determination of major carotenoids in processed tropical leafy vegetables indigenous to Africa. Food and Nutrition Sciences, 2(8), 793-802. 
[23] Puupponen Pimia R, Hakkinen ST, Aarni M, Suortti T, Lampi AM, Eurola M, Piironen V, Nuutila AM and Oksman Caldentey KM. (2003). Blanching and long-term freezing affect various bioactive compounds of vegetables in different ways. Journal of the Science of Food and Agriculture, 83(14), 1389-1402.

[24] Talcott ST and Howard LR. (1999). Phenolic autoxidation is responsible for color degradation in processed carrot puree. Journal of Agricultural and Food Chemistry, 47(5), 2109-2115.

[25] Zhang D and Hamauzu Y. (2004). Phenolics, ascorbic acid, carotenoids and antioxidant activity of broccoli and their changes during conventional and microwave cooking. Food Chemistry, 88(4), 503-509.

[26] Sikora E, Cieslik E, Leszczynska T, Filipiak Florkiewicz A and Pisulewski PM. (2008). The antioxidant activity of selected cruciferous vegetables subjected to aqua thermal processing. Food Chemistry, 107(1), 55-59.

\section{How to cite this article}

Kamrunnaher M, Rashid M, Sayem A and Islam MZ. (2019 Effect of boiling on bioactive compounds and radical scavenging activity of anthocyanin-rich vegetables: Red amaranth and red skin potato. GSC Biological and Pharmaceutical Sciences, 7(2), 127-137. 